\title{
Performance Evaluation of Design AD System Biogas Purification Filter
}

\author{
Ejiroghene Kelly Orhorhoro ${ }^{1 *}$, Oghenero Wilson Orhorhoro ${ }^{2}$, \\ Eruero Victor Atumah ${ }^{2}$
}

\author{
${ }^{1}$ Department of Mechanical Engineering, Faculty of Engineering, University of Benin, Nigeria \\ ${ }^{2}$ Faculty of Engineering, Delta State Polytechnic, Otefe-Oghara, Nigeria \\ "Corresponding author: ejiroghene.orhorhoro@eng.uniben.edu, kelecom@yahoo.com
}

(Received October 21, 2016; Accepted December 2, 2016)

\begin{abstract}
Biogas purification which is the removal of impurities so as to improve the efficiency of gas produced, ensure the safety of end users and prolong the life of the equipment cannot be neglected. This paper is focused on the design and performance evaluation of $\mathrm{AD}$ system biogas purification filter. Three different conceptual designs were generated from possible design consideration, feasibility study and preliminary test and with the help of decision matrix; the best conceptual design was selected from which the purification filter was fabricated. The selected concept for detail design was a transparent polyethene cylindrical purification filter fitted with local iron sponge containing activated charcoal and local potash. The reagents were arranged in this order; local potash for the removal of water vapour and carbon dioxide followed by activated charcoal which serves as a purifying agent for hydrogen sulphide. The results obtained showed reduction in percentage composition of hydrogen sulphide $\left(\mathrm{H}_{2} \mathrm{~S}\right)$, carbon dioxide, and water vapour. On the other hand, there was an increase in percentage composition of methane $\left(\mathrm{CH}_{4}\right)$ which is an indication of improvement in methane production after purification. The outcomes of the results obtained were satisfactory and the combination of local potash and activated charcoal was adequate for biogas purification.
\end{abstract}

Keywords- AD system, Purification filter, Design, Local reagents, Biogas.

\section{Introduction}

The Anaerobic Digestion (AD) system is a greenhouse technology which has to deal with the generation of methane rich biogas through the biological degradation of regionally available biomass such as food waste, agricultural waste, wastewater, etc. (Bamgboye, 2012; Ray et al., 2013; Orhorhoro et al., 2016). It is a waste management technique that can be adopted for the treatment and utilization of Municipal Solid Waste (MSW), and it has equally been proven to be a promising method for waste reduction and energy recycling (Zhou et al., 2014). The technology is widely adopted by Germany, Sweden, USA, Denmark etc., which have implemented rigorous waste disposal legislation (Igoni et al., 2008; Bhattacharya et al., 2005). Since 2000, annual power generation reported from AD plants/reactors projects in USA has increased almost 25 fold from 14 million kilowatt-hours (KWh) to an estimated 331 million $\mathrm{kWh}$ per year (US EPA, 2003). The technology is yet to yield reasonable results in Nigeria despite her huge biogas potential that is estimated at 25.53 billion $\mathrm{m}^{3}$ per year (Ngumah et al., 2013). AD system technology is still at the elementary stage in Nigeria as major breakthrough has not been achieved in terms of production, purification, commercialization and availability in comparison to other countries with advance technology of AD system. Countries such Germany, USA, Sweden etc. depend on renewable energy from $\mathrm{AD}$ processes. However, various research works on the technology and policy aspects of biogas production has been carried out by various researchers in Nigeria (Sambo, 2005; Akinbami, 2001). One aspect of AD system that requires special attention in Nigeria is the technology for the removal of impurities associated with the production of biogas. Little is known about the effort to develop a local technology for the purification and removal of dangerous 
International Journal of Mathematical, Engineering and Management Sciences

Vol. 3, No. 1, 17-27, 2018

https://dx.doi.org/10.33889/IJMEMS.2018.3.1-003

impurities (e.g., Hydrogen sulphide, carbon dioxide, water vapour, siloxane, etc.) as sociated with biogas produce.

Biogas is a mixture of gases evolved from AD of organic matter by anaerobic bacteria at anaerobic conditions (Adelekan and Bamgboye, 2009). Biogas is mainly composed of methane $\left(\mathrm{CH}_{4}\right)$, carbon dioxide $\left(\mathrm{CO}_{2}\right)$ and low amount of other gases (Zhou et al., 2014). In percentage by composition, biogas composed $40-70 \%$ of $\mathrm{CH}_{4}, 30-60 \%$ of $\mathrm{CO}_{2}$, and 5-10\% of other gases as shown in Table 1 (Ray et al., 2013). The quality of biogas generated by organic waste materials does not remain constant but varies with the period of digestion (Rabah et al., 2010). The ratio of $\mathrm{CH}_{4}$ to $\mathrm{CO}_{2}$ is normally stable in the reactor; any variation in the ratio is due to process imbalance (Qiao et al., 2011). However, $\mathrm{CH}_{4}$ ratio also depends on substrate composition, temperature, $\mathrm{pH}$ and pressure (Liu et al., 2009). Since the dissolution of $\mathrm{CO}_{2}$ is strongly dependent on $\mathrm{pH}$, fluctuation of $\mathrm{pH}$ can also change gas composition (Schomaker et al., 2000). Methane is a powerful greenhouse gas if emitted into the atmosphere directly, but can also represent a valuable renewable energy source, with the potential to reduce greenhouse gas emissions when it is collected and substituted for fossil fuels which have reduced the ozone layer.

\begin{tabular}{|c|c|c|}
\hline Substance & Symbol & Percentages \\
\hline Methane & $\mathrm{CH}_{4}$ & $50-70$ \\
\hline Carbon dioxide & $\mathrm{CO}_{2}$ & $25-45$ \\
\hline Hydrogen & $\mathrm{H}_{2}$ & $0-1$ \\
\hline Nitrogen & $\mathrm{N}_{2}$ & $0-1$ \\
\hline Water vapour & $\mathrm{H}_{2} \mathrm{O}$ & $0-3$ \\
\hline Hydrogen sulphide & $\mathrm{H}_{2} \mathrm{~S}$ & $0-3$ \\
\hline Ammonia & $\mathrm{NH}_{3}$ & $0-0.5$ \\
\hline Siloxane & $\mathrm{R}_{2} \mathrm{SiO}_{3}$ & $0-5$ \\
\hline
\end{tabular}

Table 1. Composition of biogas

Biogas can be used directly to generate power, cook, etc., but the large volume of $\mathrm{CO}_{2}$ produced with it reduces the heating value of the gas. It also increases compression and transportation costs and limits economic usability (Kim et al., 2004). Purification allows for a wider variety of uses, either for heating and lighting, or as vehicle fuels. For use as a fuel, purification to remove $\mathrm{CO}_{2}$ and $\mathrm{H}_{2} \mathrm{~S}$ is required, because $\mathrm{H}_{2} \mathrm{~S}$ corrodes vital mechanical components within engine if it is not removed (Yuan and Bandosz, 2007). Moreover, removing $\mathrm{CO}_{2}$ increases the heating value and leads to a consistent gas quality, similar to natural gas (Appels et al., 2008). Although $\mathrm{H}_{2} \mathrm{~S}$ is present in small quantity, it presence usually prohibits the direct use of the gases because of its toxic properties, and also it leads to the formation of sulphur (iv) oxide $\left(\mathrm{SO}_{2}\right)$ upon combustion (acid rain), and the problems it usually gives in downstream processing (Zaouak et al., 2012).

Beside, $\mathrm{H}_{2} \mathrm{~S}$ is frequently encountered in the field of odour monitoring because of its high odorous power. The type and the amount of pollutants depend upon the biogas source and this determines which cleaning and upgrading techniques are the most suitable for gas purification (Gamba and Pellegrini, 2013). Purified biogas provides reductions in GHG emissions as well as several other environmental benefits when used as a cooking fuel, vehicle fuel, lightening fuel etc. Hence there is need for proper purification of biogas, thus this research work. Also, AD system importance to institution, household and industrial process cannot be neglected. The production of biogas from AD system is of growing interest to many developed countries like Sweden, Germany, Switzerland, USA, Canada, China, Japan, etc. and developing countries like Nigeria, Nepal, Sudan, Ethiopia, Ghana etc., as wood fuel, and fossil-fuel resources decline and their resulting effect on the ozone 
layer (Sambo, 2006; ECN, 2008; Igoni et al., 2008; Bruni et al., 2010). The increasing world-wide awareness and concern about the environmental impacts of fossil fuels, wood fuel, and nuclear power, and the danger recorded from it use. For instance, the danger recorded in tsunami, Japan, as a result of the meltdown of a nuclear reactor at Fukushima and this has shifted the attention of the world to renewable energy (Akinbami et al., 2001; NISA 2011). Therefore, a renewable source of energy such as AD system technology will be a welcome development.

\section{Design Considerations}

These design factors were considered in the design process

(i) Availability of materials

(ii) Functionality

(iii) Performance

(iv) Ease of use

(v) Safety

(vi) Cost

(vii) Reliability

\subsection{Availability of Materials}

The most important consideration is the availability of the materials locally. The biogas filter is fabricated from local materials that can be obtained in every part of Nigeria. The filter was designed to be reused. The materials used were polyethene cylindrical container, mild steel nipple, iron sponge, and glue, potash, coconuts shell, oven, blender.

\subsection{Functionality}

Functionality is the ability of the biogas filter to serve a utilitarian purpose; it must be capable of purifying the biogas and at the same time ensuring the safety of the user. The purification filter is designed to serve this purpose.

\subsection{Performance}

Special consideration was taken to ensure that optimum performance was obtained. In order to achieve this, the purification filter was designed to accommodate many local iron sponges attached with local purifying materials.

\subsection{Ease of Use}

Ease of use is another essential physical consideration. The purification filter was designed to be user friendly to operators.

\subsection{Safety}

Biogas is highly inflammable and also lighter than air. Precautionary measures were taken to ensure the safety of end users. Safety is an important consideration in design process, for that reason, precaution was taken to ensure bad design; wrong decision, risk taken etc., to avoid causalities (Kopachevsky et al., 2016).

\subsection{Cost}

The filter is made with polythene plastic, local sponge, local reagents which are not only cheap but available in all parts of Nigeria, and equally affordable. 
International Journal of Mathematical, Engineering and Management Sciences

Vol. 3, No. 1, 17-27, 2018

https://dx.doi.org/10.33889/IJMEMS.2018.3.1-003

\subsection{Reliability}

Reliability is the ability of purification filter to consistently purify biogas under some stated conditions without failure and this was given special considerations in the design of these filters.

\section{Conceptualization}

The aim was to fabricate and investigate a cheap AD system biogas purification filter made with local materials. To achieve the said aim, three different concepts were generated from which the best concept was chosen for fabrication.

\subsection{Design Concept One}

In the first concept, the inlet nipple and outlet nipple are on the same side of the polythene plastic. The components/parts are inlet gas nipple, polyethene cylindrical container, outlet gas nipple and local reagents materials without local iron sponge. Fig. 1 shows design concept one.

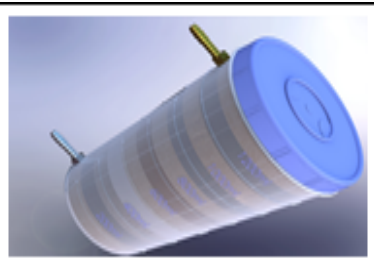

(a.) Modelview

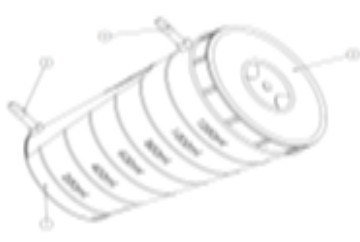

(b.) Skeletal view

\begin{tabular}{|l|l|}
\hline Part number & Part name \\
\hline 1 & Polythene case loaded withpurifier \\
\hline 2 & Cover \\
\hline 3 & Gas inlet nipple \\
\hline 4 & Gas outlet nipple \\
\hline
\end{tabular}

Fig. 1. Design concept one

\subsection{Design Concept Two}

The second concept is the modification of the first concept. Same component parts as the first concept, except the inlet nipple and outlet nipple are now in opposite side with attachment of local iron sponges and reagents materials. The local reagents were not arranged in a specific order. Fig. 2 shows design concept two.

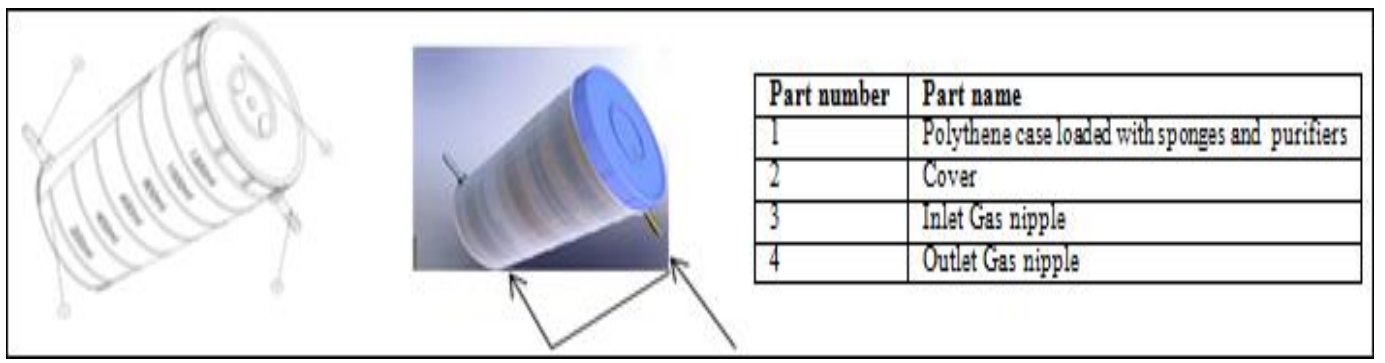

Fig. 2. Design concept two

\subsection{Design Concept Three}

The third concept was modified from first and second concepts. Concept 3 has the same component parts as the second concept but different from first concept. The inlet nipple and outlet nipple are placed parallel to each other. In this case, the inlet nipple and outlet nipple are positioned on the base and cover of the polyethene plastics loaded with local reagents material and local iron sponges that give the system orientation of biogas movement in the container and as well support the local 
International Journal of Mathematical, Engineering and Management Sciences

Vol. 3, No. 1, 17-27, 2018

https://dx.doi.org/10.33889/IJMEMS.2018.3.1-003

materials. Also, the local reagents were arranged in a specific order of removal of water vapour first, followed by carbon dioxide and lastly hydrogen sulphide. Fig. 3 shows design concept three.

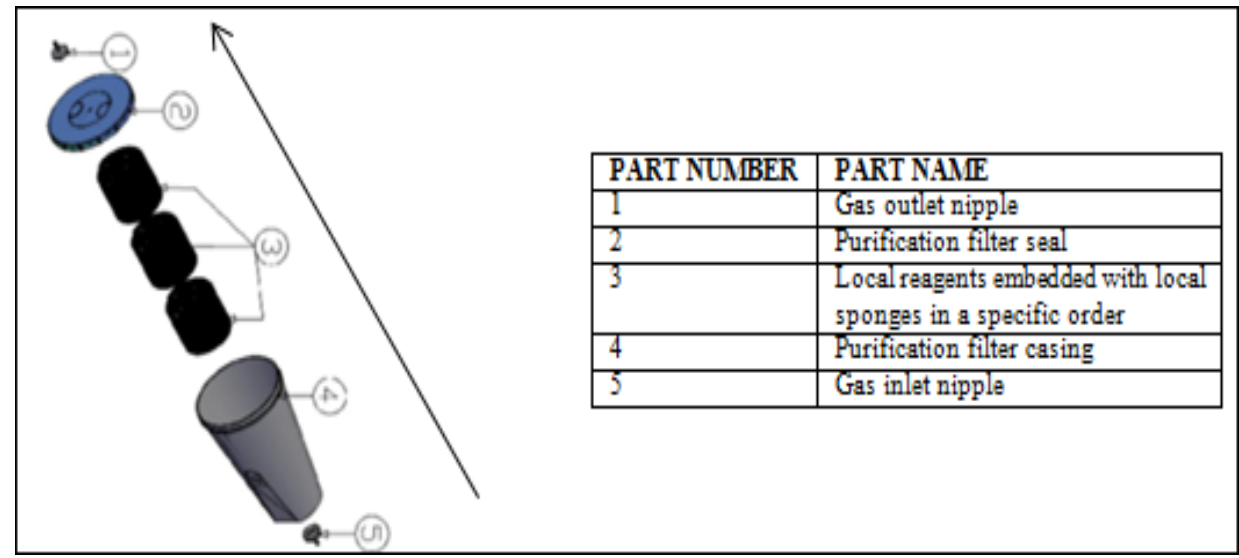

Fig. 3. Design concept three

\subsection{Concept Selection}

To ensure the best concept was chosen for fabrication, a decision matrix was drawn based on the following design considerations
(i) Functionality
(ii) Performance
(iii) Reliability
(iv) Safety
(v) Cost.

\subsection{Decision Matrix}

A decision matrix comprises a list of values in rows and columns (matrix pattern) that can be used for the analysis of a system, rating, and assessing the performance of relationships between sets of values and information. Each category is assigned a weighing factor based on self-belief which measures its relative importance. A detail of the matrix used was shown in Table 2.

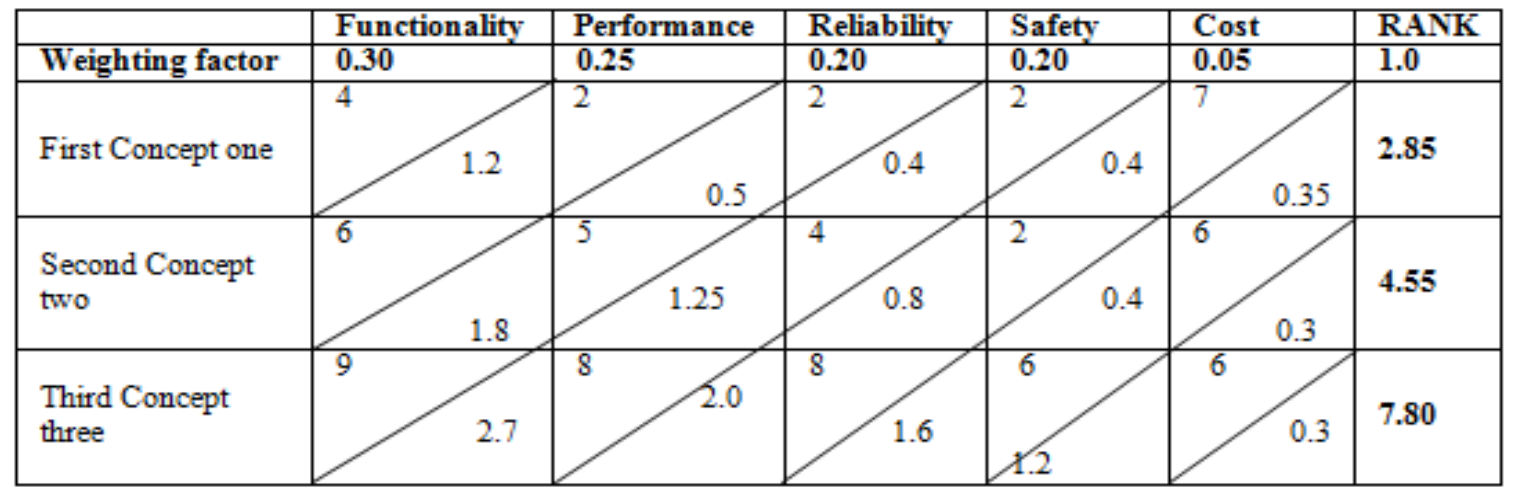

Table 2. Decision matrix 
Based on the results of the decision matrix, third concept design with the highest cumulative score rank (i.e., 7.80) was selected.

\subsection{Basis for the Ranking}

In the first concept, functionality is scored low because nothing separates the local reagents and as such, the purification filter will not be effective, performance and reliability ranking were equally low. Also, safety scored is low as well, and this has to do with the fact that the inlet and outlet nipples are positioned by the side of the plastic which is cylindrical. The curved surface will not allow the nipples to lie very well on the plastic unlike flat surface and this can bring about gas leakages during purification process. Finally, cost is scored high because this concept is more cost effective than the other two.

In the second concept, functionality is scored average because the local reagents are not arranged in a specific order that will make the filter to be effective and efficient. This arrangement also makes the performance and reliability score to be within average. This implies that the purification filter will not be able to function optimally.

For the third concept, functionality is scored high, and this is because the local reagents are arranged in a specific order; removal of water vapour first, followed by carbon dioxide and lastly hydrogen sulphide. Based on the arrangement, the performance and reliability score were high. With the positioning of the outlet and inlet nipples, gas leakage is eliminated and the filter is safe for use.

\subsection{Purification Filter Dimension}

The purification filter is a transparent plastic bottle and is dimension as follow.

(i) Diameter $=150 \mathrm{~mm}$

(ii) Radius $=75 \mathrm{~mm}=0.075 \mathrm{~m}$

(iii) Height $=400 \mathrm{~mm}$

(iv) Thickness $=1.5 \mathrm{~mm}$.

(v) Nipple length $=30 \mathrm{~mm}$

(vi) Nipple thickness $=8 \mathrm{~mm}$

Volume of filter $V=\pi r^{2} h=\pi \times 0.075^{2} \times 0.4=7.068^{-3} \mathrm{~m}^{3}$

Fig. 4 shows the (a) orthographic projection and (b.) exploded view 
International Journal of Mathematical, Engineering and Management Sciences

Vol. 3, No. 1, 17-27, 2018

https://dx.doi.org/10.33889/IJMEMS.2018.3.1-003
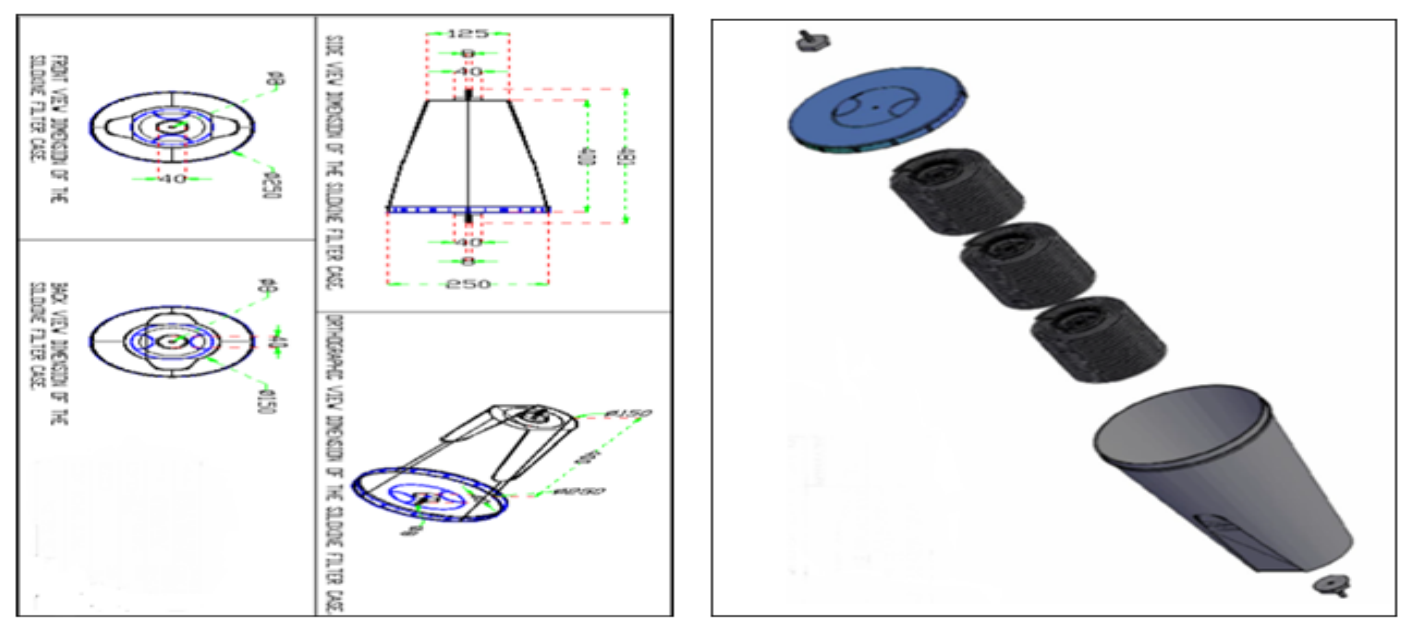

(a.) Orthographic projection

(b.) Exploded view

Fig. 4. Orthographic projection and exploded view

Fig. 5 shows (a.) fabricated AD system biogas purification filter while (b.) is the analysis of the gas composition by a gas chromatography.

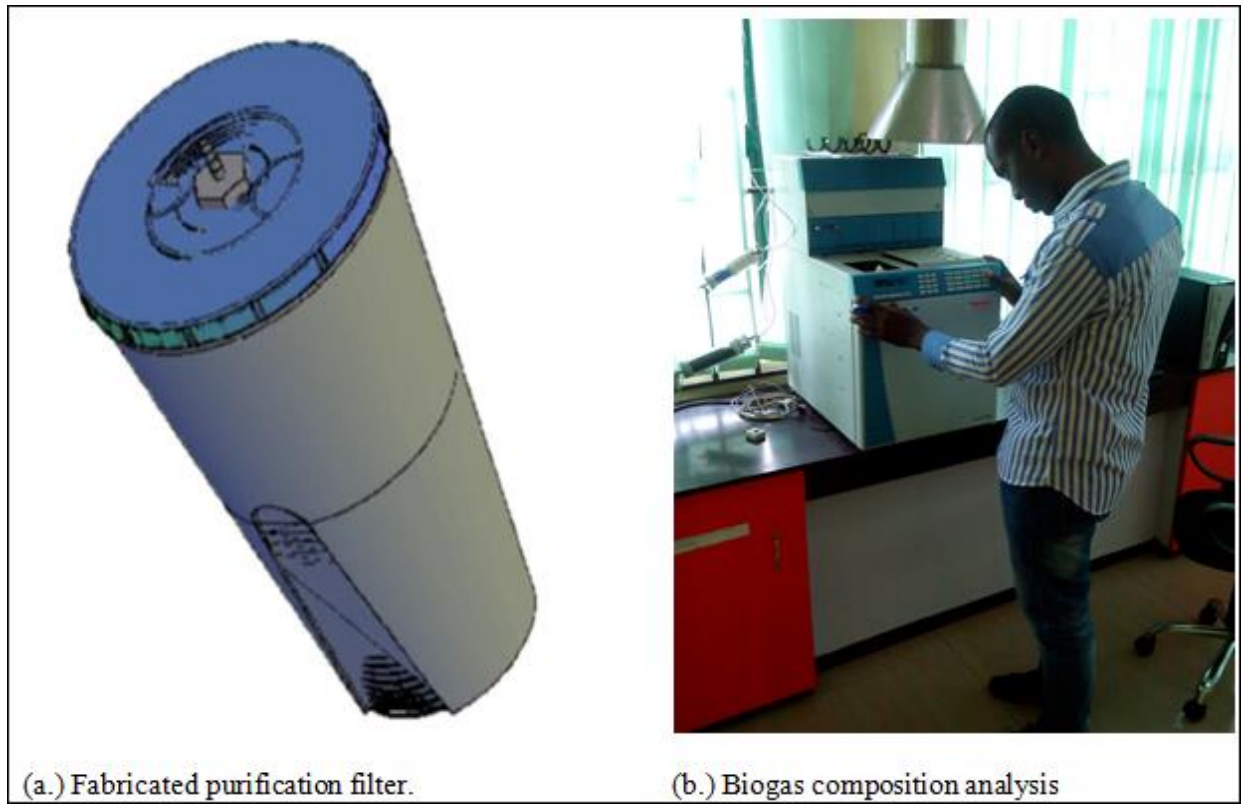

Fig. 5. Fabricated purification filter and biogas composition analysis

\subsection{Preparation of the Purification Filter}

The activated charcoal and potash were impregnated on separate local iron sponge and placed in the cylindrical polyethene container in this order; the iron sponge with potash was inserted first followed with that of the activated charcoal. This is because for dominant adsorption of $\mathrm{H}_{2} \mathrm{~S}$ with $\mathrm{H}_{2} \mathrm{O}$ which could lead to the formation of acid rain. Also, the following conditions must be satisfied. 
International Journal of Mathematical, Engineering and Management Sciences

Vol. 3, No. 1, 17-27, 2018

https://dx.doi.org/10.33889/IJMEMS.2018.3.1-003
(i) Dry
(ii) Vacuum
(iii) Low temperature, and
(iv) Anaerobic

Analysis of the composition of biogas before and after purification was recorded to ascertain the potency of the design filter.

\subsubsection{Preparation of Activated Charcoal from Coconut Shell}

The coconut shell was washed thoroughly with clean water and allowed to dry completely in order to facilitate combustion. The coconut shell was burned into completely ashes. A standard preparation $250 \mathrm{~g}$ of calcium chloride $\left(\mathrm{CaCl}_{2}\right)$ was dissolved in $1000 \mathrm{ml}$ of water as chemical activator. The dissolved $\mathrm{CaCl}_{2}$ solution was poured into plastic pail containing the cooled coconut shell ash. The pail was covered and left to cool for one day. During this process, the chemical is impregnated into the ash and it will transform the ash into activated charcoal. The charcoal from the coconut shell was removed from the chemical solution and transferred into a draining tray were it was allowed to drain for about one hour. The charcoal was washed in sterilized water repeatedly to remove chemicals. The charcoal was finally transferred into an oven, with the temperature set at $105^{\circ} \mathrm{C}$ for adequate drying. The dried charcoal was crushed with a blender and impregnated with iron sponge mainly to support the tiny particles. Table 3 shows how the purification reagents materials were used.

\begin{tabular}{|l|l|}
\hline Reagents & Purification ability \\
\hline Local potash & To purify water vapour and carbon dioxide \\
\hline Activated coconut charcoal & To purify hydrogen sulphide \\
\hline
\end{tabular}

Table 3. Purification ability of the reagent used

\section{Results and Discussion}

The quantity of impure biogas evacuated for percentage composition analysis was $4 \mathrm{~kg}$. This was divided into four different storage containers $(1 \mathrm{~kg}$ each) and four different purification tests were carried out with activated charcoal and potash. The same quantity of activated charcoal and potash each measuring $250 \mathrm{~g}$ was used. The results of the purification with Activated charcoal and Potash are shown in Table 4

\begin{tabular}{|c|c|l|l|l|l|c|c|c|c|}
\hline \multirow{2}{*}{ Test } & \multirow{2}{*}{ Biogas mass (kg) } & \multicolumn{4}{|c|}{ Raw Biogas } & \multicolumn{3}{c|}{ BIOGAS PURIFIELD WITH Activated Charcoal and Potash } \\
\cline { 3 - 9 } & & $\mathbf{C H}_{\mathbf{4}}$ & $\mathbf{C O}_{\mathbf{2}}$ & $\mathbf{H}_{\mathbf{2}} \mathbf{S}$ & $\mathbf{H}_{\mathbf{2}} \mathbf{O}$ & $\mathbf{C H}_{\mathbf{4}}$ & $\mathbf{C O}_{\mathbf{2}}$ & $\mathbf{H}_{\mathbf{2}} \mathbf{S}$ & $\mathbf{H}_{\mathbf{2}} \mathbf{O}$ \\
\hline 1 & 1.0 & 67.50 & 31.00 & 0.57 & 0.93 & 81.25 & 18.73 & 0.01 & 0.01 \\
\hline 2 & 1.0 & 67.50 & 31.00 & 0.57 & 0.93 & 81.20 & 18.77 & 0.02 & 0.01 \\
\hline 3 & 1.0 & 67.50 & 31.00 & 0.57 & 0.93 & 81.00 & 18.95 & 0.02 & 0.03 \\
\hline 4 & 1.0 & 67.50 & 31.00 & 0.57 & 0.93 & 81.35 & 18.61 & 0.02 & 0.02 \\
\hline Ave. & 1.0 & 67.50 & 31.00 & 0.57 & 0.93 & 81.20 & 18.77 & 0.0175 & 0.0175 \\
\hline
\end{tabular}

Table 4. Purification results of testing with activated charcoal and potash

The results show that the percentage composition of hydrogen sulphide $\left(\mathrm{H}_{2} \mathrm{~S}\right)$ decreases from $0.57 \%$ to $0.01-0.02 \%$, carbon dioxide from $31.00 \%$ to $18.61-18.95 \%$, water vapour from $0.93 \%$ to $0.01-0.03 \%$ and for methane $\left(\mathrm{CH}_{4}\right)$, it increases from $67.50 \%$ to $81.00-81.35 \%$. The increase in the percentage composition of methane, decrease in the compositions of carbon dioxide, hydrogen sulphide, and water vapour shown the purification filter performance was efficient. 
International Journal of Mathematical, Engineering and Management Sciences

Vol. 3, No. 1, 17-27, 2018

https://dx.doi.org/10.33889/IJMEMS.2018.3.1-003

\section{Conclusion}

This study sets on the design of local AD system biogas purification filter suitable for use in Nigeria shows that biogas purification filter can be design and fabricate locally in Nigeria. Also, impure biogas can be purified with potash, and activated charcoal. The percentage composition analysis of biogas before and after purification with potash and activated charcoal shows improvement of methane. The analysis shows that water vapour $\left(\mathrm{H}_{2} \mathrm{O}\right)$ in biogas can be removed with potash, while for $\mathrm{H}_{2} \mathrm{~S}$ that has effect of forming acidic rain if not properly removed from biogas was removed by activated charcoal. Therefore, the possibility of meeting some of our energy needs can be achieved with the help of the low cost locally AD system biogas purification filter for household use in Nigeria.

\section{Recommendation}

Nigeria biogas potential is estimated at 25.53 billion $\mathrm{m}^{3}$ per year. With this huge biogas production potential, the department and the government at all levels should take active part in all biogas projects and intensify findings of researches to enhance the production of biogas. Biogas plants should be constructed across Nigeria cities to decrease the volume of domestic wastes that should be disposed and in the process methane liberated into the atmosphere is reduced which has huge negative impact on the greenhouse gas than carbon (IV) oxide. In future research, the filter should be tested several times to know how long it can be reused and with that the life span can be determined.

\section{References}

Adelekan, B. A. \& Bamgboye, A.I. (2009). Comparison of biogas productivity of cassava peels mixed in selected ratios with major livestock waste types. African Journal of Agricultural Research, 4(7), 571577.

Akinbami, J. F. K. (2001). Renewable energy resources and technologies in Nigeria: present situation, future prospects and policy framework. Mitigation and Adaptation Strategies for Global Change, 6(2), 155182.

Akinbami, J. F., Ilori, M. O., Oyebisi, T. O., Akinwumi, I. O., \& Adeoti, O. (2001). Biogas energy use in Nigeria: current status, future prospects and policy implications. Renewable and Sustainable Energy Reviews, 5(1), 97-112.

Appels, L., Baeyens, J., Degrève, J., \& Dewil, R. (2008). Principles and potential of the anaerobic digestion of waste-activated sludge. Progress in Energy and Combustion Science, 34(6), 755-781.

Bamgboye, I. A. (2012). The potential of producing fuel from biomass in Nigeria. In Jekayinfa SO Ed). Building a non-oil export based economy for Nigeria: the potential of value -added products from agricultural residues. Cuvillier Verlag Gottingen. pp. 35-41

Bhattacharya, S. C., Salam, P. A., Runqing, H., Somashekar, H. I., Racelis, D. A., Rathnasiri, P. G., \& Yingyuad, R. (2005). An assessment of the potential for non-plantation biomass resources in selected Asian countries for 2010. Biomass and Bioenergy, 29(3), 153-166.

Bruni, E., Jensen, A. P., Pedersen, E. S., \& Angelidaki, I. (2010). Anaerobic digestion of maize focusing on variety, harvest time and pretreatment. Applied Energy, 87(7), 2212-2217. 
International Journal of Mathematical, Engineering and Management Sciences

Vol. 3, No. 1, 17-27, 2018

https://dx.doi.org/10.33889/IJMEMS.2018.3.1-003

Energy Commission of Nigeria (2008). Communiqué of National workshop on sustainable Jatropha for energy development. 6th -7th May, Mambayya house, Kano. www.energy.gov.ng. Accessed on 3rd January 2015.

Gamba, S., \& Pellegrini, L. A. (2013). Biogas upgrading: Analysis and comparison between water and chemical scrubbings. Chemical Engineering Transactions, 32, 1273-1278.

Igoni, A. H., Ayotamuno, M. J., Eze, C. L., Ogaji, S. O. T., \& Probert, S. D. (2008). Designs of anaerobic digesters for producing biogas from municipal solid-waste. Applied Energy, 85(6), 430-438.

Kim, S., Kim, H. T., \& Chi, B. (2004). Optimization of CO2 absorption process with MEA solution. Carbon Dioxide Utilization for Global Sustainability, 153, 429-434.

Kopachevsky, I., Kostyuchenko, Y. V., \& Stoyka, O. (2016). Land use drivers of population dynamics in tasks of security management and risk assessment. International Journal of Mathematical, Engineering and Management Sciences, 1(1), 18-25.

Liu, G., Zhang, R., El-Mashad, H. M., \& Dong, R. (2009). Effect of feed to inoculum ratios on biogas yields of food and green wastes. Bioresource Technology, 100(21), 5103-5108.

Ngumah, C., Ogbulie, J. N., Orji, J. C., \& Amadi, E. S. (2013). Biogas potential of organic waste in Nigeria. Journal of Urban and Environmental Engineering, 7(1), 110-116.

Nuclear and Industrial Safety Agency (2011). The 2011 off the Pacific coast of Tohoku Pacific Earthquake and the seismic damage to the NPPs, Nuclear and Industrial Safety Agency (NISA); Japan Nuclear Energy Safety Organization (JNES), Japan.

Orhorhoro, E. K., Ebunilo, P. O., Tamuno, R. I., \& Essienubong, I. A. (2016). The study of anaerobic codigestion of non-uniform multiple feed stock availability and composition in Nigeria. European Journal of Engineering Research and Science, 1(1), 39-42.

Qiao, W., Yan, X., Ye, J., Sun, Y., Wang, W., \& Zhang, Z. (2011). Evaluation of biogas production from different biomass wastes with/without hydrothermal pretreatment. Renewable Energy, 36(12), 33133318 .

Rabah, A. B., Baki, A. S., Hassan, L. G., Musa, M., \& Ibrahim, A. D. (2010). Production of biogas using abattoir waste at different retention time. Science World Journal, 5(4), 23-26.

Ray, N. H. S., Mohanty, M. K., \& Mohanty, R. C. (2013). Anaerobic digestion of kitchen wastes: biogas production and pretreatment of wastes, a review. International Journal of Scientific and Research Publications, 3(11), 1-6.

Sambo, A. S. (2005). Renewable energy for rural development-the Nigerian perspective. ISESCO Science and Technology Vision, 1, 12-22.

Sambo, A. S. (2006). Renewable energy electricity in Nigeria, the way forward. Paper presented at the Renewable Electricity Policy Conference held at Shehu Musa Yarádua Centre, Abuja. pp. 11-12.

Schomaker, A. H. H. M., Boerboom, A. A. M., \& Visser, A. (2000). Anaerobic digestion of agro-industrial wastes: information network, technical summary on gas treatment AD-NETT, Project FAIR-CT96-2083 (GD12-SSMI).

United State Environmental regulations and technology (2003). Control of pathogens and vector attraction in sewage sludge under CFR part 503. Report No. 625/R-92/013. Cincinnati, OH: US EPA, Washington DC.

Yuan, W., \& Bandosz, T. J. (2007). Removal of hydrogen sulfide from biogas on sludge-derived adsorbents. Fuel, 86(17), 2736-2746. 
International Journal of Mathematical, Engineering and Management Sciences

Vol. 3, No. 1, 17-27, 2018

https://dx.doi.org/10.33889/IJMEMS.2018.3.1-003

Zaouak O., Ben D. A., Fages, M., Fanlo, J. L., \& Aubert, B. (2012). High performance cost effective miniature sensor for continuous network monitoring of hydrogen $\mathrm{H}_{2} \mathrm{~S}$. Chemical Engineering Transactions, 30, 325-330.

Zhou, Q., Shen, F., Yuan, H., Zou, D., Liu, Y., Zhu, B., \& Li, X. (2014). Minimizing asynchronism to improve the performances of anaerobic co-digestion of food waste and corn stover. Bioresource Technology, 166, 31-36. 